\title{
Lysyl oxidase-like-1 enhances lung metastasis when lactate accumulation and monocarboxylate transporter expression are involved
}

\author{
GEUM-HWA LEE ${ }^{1}$, DO-SUNG KIM ${ }^{1}$, MYUNG JA CHUNG ${ }^{2}$, SOO-WAN CHAE ${ }^{1}$ \\ HYUNG-RYONG KIM ${ }^{3 *}$ and HAN-JUNG CHAE ${ }^{1 *}$
}

\begin{abstract}
Departments of ${ }^{1}$ Pharmacology and Cardiovascular Research Institute, and ${ }^{2}$ Pathology, School of Medicine,
Chonbuk National University, Jeonju 560-182; ${ }^{3}$ Department of Dental Pharmacology,

School of Dentistry, Wonkwang University, Iksan 570-749, Republic of Korea
\end{abstract}

Received January 28, 2011; Accepted July 1, 2011

DOI: $10.3892 / \mathrm{ol} .2011 .353$

\begin{abstract}
The role that lysyl oxidase-like-1 (LOXL-1) may play in cancer metastasis due to its specific collagen accumulation characteristics has not been investigated extensively. This study was performed to examine the role of LOXL-1 in cancer metastasis. In vitro and in vivo cancer metastasis experiments were performed with $\mathrm{B} 16 \mathrm{~F} 10$ cells. Using the immunoblotting technique, the expression of LOXL-1, monocarboxylate transporter (MCT) $1 / 2$ and matrix metalloproteinase (MMP)2/9 was examined in a cell culture model and in primary and metastatic site samples from non-small cell lung carcinoma patients. Immunohistochemistry was also performed. According to immunohistochemical analysis of the non-small cell lung carcinoma patient samples, LOXL-1, MCT1/2 and MMP2/9 were expressed more highly in metastatic sites compared to primary sites. In in vivo studies, LOXL-1-overexpressing B16F10 cells yielded higher numbers of cancer nodules following their injection into mouse tail veins. Transfection of LOXL-1 siRNA into the cells prior to injection blocked lung metastasis. In vitro, the overexpression of LOXL-1 increased cell mobility and invasiveness, with increased extracellular accumulation of lactate at a low $\mathrm{pH}$. The lactate transporter, MCT1/2, was highly expressed in LOXL-1-overexpressing cells. LOXL-1 knockdown through siRNA inhibited cell motility and invasiveness, showing relatively lower lactate accumulation and expression of MCT1/2 than under control conditions. This study elucidates
\end{abstract}

Correspondence to: Dr Han-Jung Chae, Department of Pharmacology, School of Medicine, Chonbuk National University, Jeonju, 560-182, Republic of Korea

E-mail: hjchae@chonbuk.ac.kr

*Contributed equally

Key words: metastasis, non-small cell lung carcinoma, lysyl oxidase-like-1 extracellular $\mathrm{pH}$-associated matrix degradation as a potential mechanism for LOXL-1-induced cancer metastasis.

\section{Introduction}

Metastasis, the spread of cancer cells from the primary tumor to distant organs, remains a major clinical challenge. The transition from a localized tumor to an invasive/metastatic tumor is a landmark in the development of malignant disease, since it is associated with a markedly worse prognosis $(1,2)$. Most tumors/cancers develop a pathophysiological microenvironment characterized by hypoxic conditions, including low oxygen tension and elevated interstitial fluid pressure (3). The hypoxic condition stimulates anaerobic glycolysis, instead of oxygen-induced mitochondrial respiration. The alterations in glucose metabolism regulate cancer metastasis by causing high glucose uptake, high lactate formation and reduction of intra- and extra-tumoral $\mathrm{pH}$ (4-7). The acidic environment is produced by the activity of ion channels and transporters including $\mathrm{Na}^{+} / \mathrm{H}^{+}, \mathrm{Cl}^{-} / \mathrm{HCO}^{-}$exchangers, or the lactate transporter $\mathrm{MCT}(8,9)$. High lactic acid production is a common feature of numerous solid-tumor cells (10-12). MCT isoform 1 (MCT1) and MCT4 are highly activated in human cancer cells (13), suggesting that the level and/or affinity of proton/lactate export transporters were increased in cancer cells and that these transporters acted to prevent a lethal intracellular $\mathrm{pH}$ decrease, as tumors grow and become more acidic. To maintain the intracellular $\mathrm{pH}$ in cancer cells, extracellular $\mathrm{pH}$ becomes acidic through transporters such as MCT (14-16). In the acidic surroundings, the activities of extracellular matrix-degrading enzymes such as metalloproteases, including MMP2/9, are also highly activated, revealing the correlation of acidic $\mathrm{pH}$ with MMP activities $(3,17)$.

Lysyl oxidase-like protein-1 (LOXL-1), one of the lysyl oxidase (LOX) family proteins, was originally described as a copper-dependent amine oxidase responsible for catalyzing the cross-linking of collagens and elastins within the extracellular matrix (18). Previously, it was observed that, in epithelial tumors, the transition from a localized to an invasive/metastatic tumor is associated in many cases with the formation of 
fibrotic foci and desmoplasia (the presence of unusually dense collagenous stroma) within the primary tumor $(19,20)$. These observations may represent apparent paradoxes as invasiveness has long been associated with the destruction of the extracellular matrix (ECM) by the ECM-degrading enzymes or metalloproteases (21). However, the deposition of excess ECM may in turn stimulate the expression of matrix-degrading enzymes that contribute to tumor invasion. Evidence suggests that an increase in ECM deposition affects the production of ECM-degrading enzymes (22). Although LOX and LOXL-1 were found to be expressed in areas of fibrogenesis in noninvasive in situ ductal breast carcinomas (23), metastatic cancer cell lines express LOX or LOXL-1, whereas nonmetastatic cancer-derived cell lines do not (24). Furthermore, LOX-expressing cells exhibit increased invasiveness in in vitro invasiveness assays (24). In addition, LOXL-1 is highly expressed in metastatic breast cancer-derived cell lines (18). However, the relationship between LOX or LOXL-1 and cancer metastasis has not been clarified.

In this study, the role of LOXL-1 in cancer metastasis was examined. It was hypothesized that this role may be related to acidic extracellular $\mathrm{pH}$, probably though extracellular lactate accumulation.

\section{Materials and methods}

Materials. Monoclonal anti-LOXL-1 antibody was obtained from Professor Y. Kim (Wonkwang University, Iksan, Korea). The antibody against hemagglutinin antigen (HA) was purchased from Cell Signaling Technologies (Beverly, MA, USA). Dulbecco's modified Eagle's medium (DMEM), fetal bovine serum (FBS), trypsin and other tissue culture reagents were supplied by Life Technologies, Inc. (Grand Island, NY, USA). Bicinchoninic acid (BCA) protein assay reagents were obtained from Pierce Biotechnology (Rockford, IL, USA). All other chemicals were at least of analytical grade and were purchased from Sigma Chemical Company (St. Louis, MO, USA).

Tumor metastasis model. In the experimental lung metastasis model, B16F10 cells $\left(5 \times 10^{4}\right)$, which were transfected with a pcDNA3 vector, LOXL-1, or non-specific or LOXL-specific siRNA, were injected into the tail veins of C57BL/6 mice on day 0 . Eighteen days after cell inoculation the mice were bled, sacrificed, and the lungs were removed, weighed, and fixed in formalin solution. Tumor nodules on the five lobes of the lungs were then counted macroscopically.

Immunoblotting assays. Equal amounts of the protein that was extracted from cells with RIPA buffer was fractionated by $10 \%$ SDS-PAGE. Blots were stripped, probed with antibodies including LOXL-1 antibody and reprobed with a polyclonal antibody against $\beta$-actin (Santa Cruz Biotechnology, Santa Cruz, CA, USA) to confirm equal protein loading and transfer.

In vitro invasion assay. An in vitro invasion assay was performed using a 24-well transwell unit with polycarbonate filters (Corning Costar, Cambridge, MA, USA) as previously described (17). The lower side of the filter was coated with type I collagen and the upper side was coated with matrigel
(Collaborative Research, Lexington, KY, USA). The lower compartment was filled with serum-free medium containing $0.1 \%$ FBS. Cells were placed in the upper section of the transwell plate, incubated for $17 \mathrm{~h}$, then fixed and stained with crystal violet dye for $10 \mathrm{~min}$. Invasive phenotypes were determined by counting the cells that migrated to the lower side of the filter with microscopy at $\mathrm{x} 400$. Thirteen fields were counted for each filter and each sample was assayed in triplicate.

Wound migration assay. An injury line was made with a $2 \mathrm{~mm}$ wide tip on the cells plated in culture dishes at $90 \%$ confluence. After being rinsed with PBS, cells were allowed to migrate in complete medium and images were captured (x40) at the indicated time points.

Gelatin zymography. Cells were cultured in serum-free DMEM for $48 \mathrm{~h}$. Conditioned media were collected and centrifuged at 3,000 rpm for $10 \mathrm{~min}$ to remove cell debris. The protein concentration was measured using BCA protein assay reagents (Pierce, Rockford, IL, USA). Equal amounts of protein from the conditioned media were mixed with $2 \mathrm{X}$ Laemmli non-reducing sample buffer, incubated for $15 \mathrm{~min}$ at room temperature and then electrophoresed on $10 \%$ SDS-PAGE gels containing $1 \mathrm{mg} / \mathrm{ml}$ gelatin. Following electrophoresis, the gels were washed with $2.5 \%$ Triton X-100 three times for $30 \mathrm{~min}$, rinsed for $15 \mathrm{~min}$ with $50 \mathrm{mM}$ Tris- $\mathrm{HCl}$ buffer (pH 7.6) containing $5 \mathrm{mM} \mathrm{CaCl}, 0.02 \%$ Brij-35 and $0.2 \%$ sodium azide and incubated overnight at $37^{\circ} \mathrm{C}$. The gels were stained with $0.5 \%$ Coomassie Brilliant Blue R-250 solution containing $10 \%$ acetic acid and $20 \%$ methanol for $30 \mathrm{~min}$ and de-stained with $10 \%$ acetic acid solution. Areas of gelatinase activity were detected as clear bands against the blue-stained gelatin background.

Patients. A total of 71 non-small cell lung carcinoma patients, including patients with tumors in 55 primary regions and 16 metastatic regions, were selected for this study. Metastatic region tissues were obtained from lymph nodes. The patients underwent surgical resection at the Chonbuk National University Hospital. Clinical information was obtained through a computerized tumor registry database. Samples derived from the National Biobank of Korea were obtained with informed consent, and approval was obtained from the institutional review board

Tissue microarray construction. One representative formalin-fixed, paraffin-embedded block-containing tumor was selected for each of the 71 cases. The arrays were constructed using a $3 \mathrm{~mm}$ punch (Microm International, Korea). All 71 cases were reviewed using conventional hematoxylin and eosin-stained slides and the areas of interest were marked on each slide. The corresponding regions on the donor paraffin blocks were arrayed on recipient blank blocks. Histological typing was performed according to the histological classification of lung cancer by the World Health Organization.

Immunohistochemistry. Sections $(5 \mu \mathrm{m})$ were cut from a tissue microarray block, de-paraffinized in xylene and rehydrated 
in graded alcohols. Antigen retrieval was achieved by incubation of tissue sections in boiling $10 \mu \mathrm{mol} / 1$ citrate buffer ( $\mathrm{pH}$ 6.0) for $10 \mathrm{~min}$ in a microwave oven and immunostaining was undertaken using the avidin-biotinylated enzyme complex method (Dako, Denmark) with LOXL-1 antibody overnight at $4^{\circ} \mathrm{C}$. Following incubation with the appropriate biotin-conjugated secondary antibody and subsequently with streptavidin solution, color development was performed using 3-amino-9-ethylcarbazole (AEC) (Lab Vision, CA, USA) as a chromogen. The sections were counterstained with hematoxylin. Appropriate negative controls, consisting of tissue sections of each case, processed without the addition of primary antibody, were prepared along with positive control sections. Tumors were considered to be positive for LOXL-1 when cytoplasmic reactivity was observed in $>25 \%$ of the tumor cells at any intensity.

Statistical analysis. Associations between LOXL-1 expression and clinicopathological parameters were analyzed using the SPSS software package, version 11.5 (Seoul, Korea). P-values were determined via Chi-square tests.

\section{Results}

LOXL-1 is involved in lung cancer metastasis. Table I shows immunohistochemistry results for LOXL-1. A total of 71 cases of lung carcinoma were available for analysis. Fifty-five tissue samples were obtained from primary sites and 16 tissues were obtained from metastatic lymph nodes. LOXL-1 expression was more frequently observed in the metastatic sites $(81 \%)$ than in the primary sites $(40 \%, \mathrm{p}=0.004)$. In primary regions, LOXL-1 expression was associated with histological type $(\mathrm{p}=0.014) ; 14$ of 23 squamous cell carcinomas $(61 \%)$ and 6 of 24 adenocarcinomas (25\%) were positive for LOXL-1. No correlations were found between LOXL-1 expression and tumor size or histological grade.

LOXL-1 induces lung metastasis in vivo. An in vivo study was used to investigate the involvement of LOXL-1 in cancer metastasis. In one set of experiments, lung metastasis was examined using a tail vein injection model. For this study, transfected stable B16F10 cells that highly express LOXL-1 (LOXL cells) were used. The expression of LOXL-1 is confirmed in the upper panel of Fig. 1A. The LOXL-1-expressing tumor cells produced a greater number of metastatic lung colonies than neomycin-resistant control vector-transfected tumor cells (Neo cells; Fig. 1A and B), but without altering tumor colony size (data not shown). The endogenous role of LOXL-1 was also investigated. The same in vivo experiments were performed with non-specific or LOXL-1 siRNA-transfected B16F10 cells. Decreased expression of LOXL-1 in LOXL-1 siRNA-transfected cells was confirmed (upper panel, Fig. 1C). The injection of the LOXL-1 knock-down cells significantly reduced the number of tumor nodules compared with the non-specific siRNA-transfected cell-injected model (Fig. 1C). The quantified number of nodules is shown in Fig. 1D.

LOXL-1 induces cancer metastasis in vitro. In vitro analysis of tumor cell migration was conducted using infiltration
Table I. Correlation between the expression of LOXL-1 and clinicopathological parameters in non-small cell lung carcinoma.

\begin{tabular}{|c|c|c|c|c|}
\hline & \multirow{2}{*}{$\begin{array}{c}\text { No. } \\
\text { of } \\
\text { cases }\end{array}$} & \multicolumn{2}{|c|}{ LOXL-1 expression } & \multirow[t]{2}{*}{ p-value } \\
\hline & & Negative & Positive & \\
\hline Tumor size & & & & 0.435 \\
\hline$\leq 3.0 \mathrm{~cm}$ & 27 & 17 & 10 & \\
\hline$>3.0 \mathrm{~cm}$ & 28 & 16 & 12 & \\
\hline Histological type & & & & 0.019 \\
\hline $\begin{array}{l}\text { Squamous cell } \\
\text { carcinoma }\end{array}$ & 23 & 9 & 14 & \\
\hline Adenocarcinoma & 24 & 18 & 6 & \\
\hline Other & 8 & 6 & 2 & \\
\hline Histological grade & & & & 0.301 \\
\hline Well & 10 & 8 & 2 & \\
\hline Moderate & 28 & 16 & 12 & \\
\hline Poor & 16 & 8 & 8 & \\
\hline $\begin{array}{l}\text { Lymph node } \\
\text { metastasis }\end{array}$ & & & & 0.177 \\
\hline Negative & 40 & 26 & 14 & \\
\hline Positive & 15 & 7 & 8 & \\
\hline Tumor site & & & & 0.004 \\
\hline Primary site & 55 & 33 & 22 & \\
\hline Metastatic site & 16 & 3 & 16 & \\
\hline
\end{tabular}

and wound healing assays. In the infiltration assay, Neo and LOXL cells were added to the upper surface of a matrigel-coated chamber in a medium containing $0.1 \%$ serum (Corning Costar, Cambridge, MA, USA) and were allowed to adhere as previously described (17). Invasion was measured over $17 \mathrm{~h}$ by placing the lower chamber in contact with medium containing $0.1 \%$ FBS. Cells were stained with Coomassie blue and the number of adherent cells was counted. In the infiltration assay, the quantification data clearly showed a significant increase in infiltrated cells in the LOXL cell chambers (Fig. 2A, lower panel). A complementary wound healing assay of in vitro cell migration was performed in which a $300 \mu \mathrm{m}$-wide linear strip of cells was scraped from confluent monolayers using a pipette tip. In agreement with the infiltration assay, the wound healing assay revealed significantly increased wound closure in the LOXL cells, compared with the Neo cells at 3, 6, 9 and $12 \mathrm{~h}$ following scratching (Fig. 2B).

Increased glycolysis is a phenotypic trait almost invariably observed in human cancers with an acidic environment that is toxic to competitors but relatively harmless to the tumors themselves. Therefore, we compared the extracellular lactate accumulation between Neo and LOXL cells. The amount of lactate was time-dependently increased in the extracellular medium (Fig. 2C). Particularly in LOXL cells, the lactate increase pattern was significantly clearer than in the Neo cells. The extracellular $\mathrm{pH}$ value was also consistently lower in LOXL cells than in Neo cells following the culturing period of $36 \mathrm{~h}$ (Fig. 2D). The expression of 
A
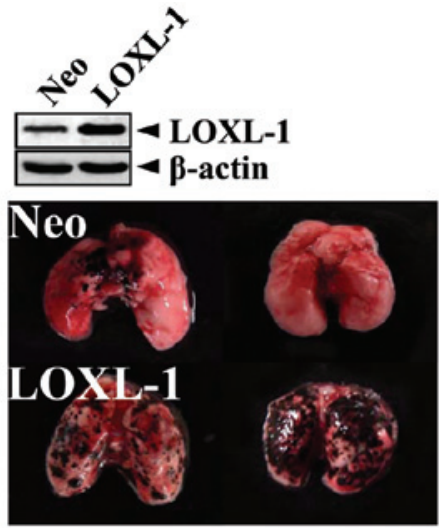

C
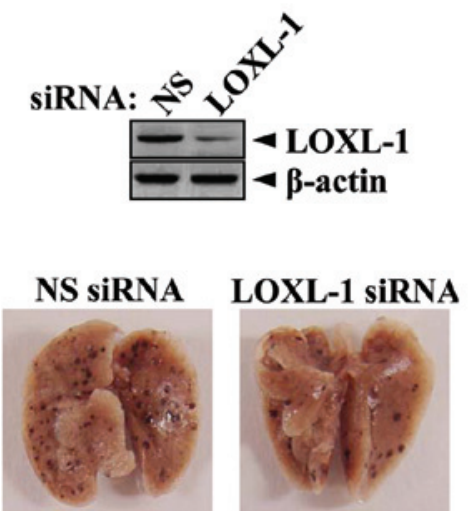

B

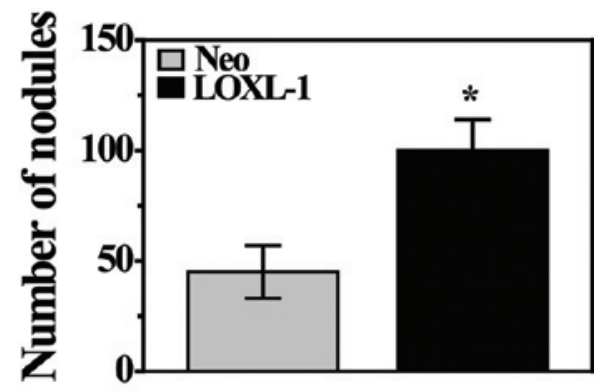

D

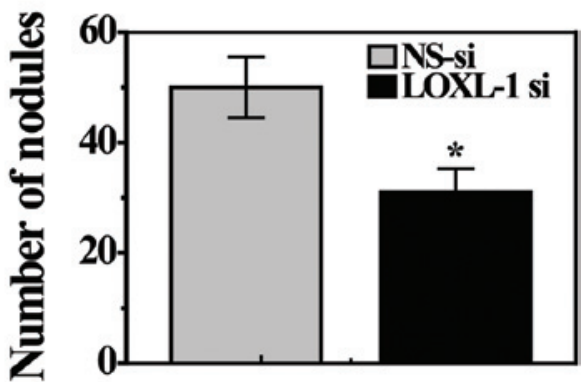

Figure 1. LOXL-1 induces lung metastasis in vivo. Neo and LOXL-1-transfected B16F10 cells (expression was confirmed, upper panel) were injected into mouse tail veins. Eighteen days later, (A) images of the lungs were captured and the nodules were quantified. (B) Non-specific or LOXL-1 siRNA-transfected B16F10 cells (expression confirmed, lower panel) were injected into mice tail veins. Eighteen days later, (C) images of the lungs were captured and the (D) nodules were quantified. Arrowheads, metastatic nodules in the lung. ${ }^{*} \mathrm{P}<0.05$, significantly different from the lung nodule number in the Neo cell-injected model. Neo, neomycin-resistant vector-transfected; NS-si, non-specific siRNA.

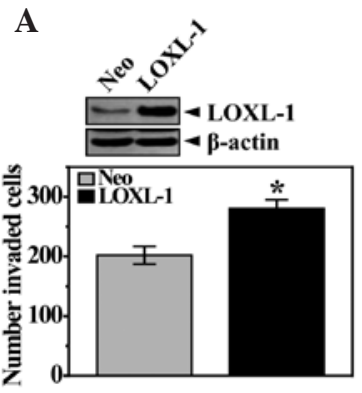

C

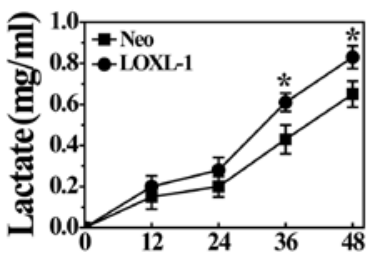

Time (h)

$\mathbf{E}$

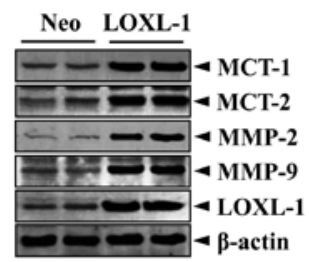

B

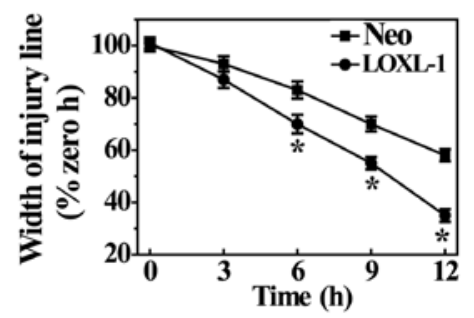

D

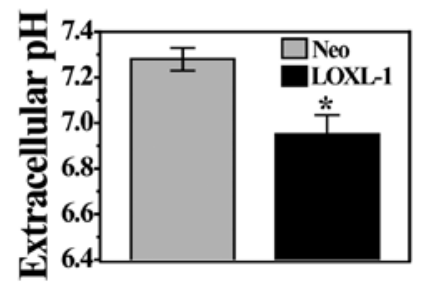

F

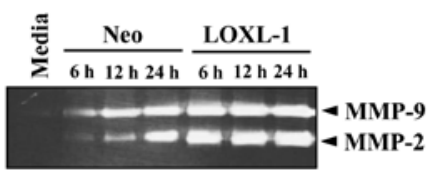

MCT1/2 was then assessed. MCT1/2 regulates the transport of the monoamine compounds including lactate to the extracellular surroundings, which explains how lactate is accumulated in the medium (25). As expected, the expression of MCT1/2 was high, along with MMP2/9, suggesting pH-associated ECM degradation and cancer metastasis (Fig. 2E and F). To show the endogenous role of LOXL-1 in cancer metastasis, in vitro analysis of tumor cell invasion was conducted with an infiltration assay using siRNA. The knockdown of LOXL expression is confirmed in Fig. 3A (upper panel). LOXL-1 siRNA-transfected cells revealed a significantly lower infiltration efficiency than non-specific siRNA-transfected cells (Fig. 3A, lower panel). The quantification data clearly showed the significance in the LOXL-1

Figure 2. LOXL-1 accelerates in vitro migration and invasion when lactate and MCT expression are involved. (A) Neo and LOXL cells that invaded through the matrigel-coated membrane were stained with $0.1 \%$ crystal violet. The amount was then determined by counting the stained cells in the lower well. (B) Through phase-contrast micrographs of scratched monolayers of Neo and LOXL-1-expressing cells at 0 and $15 \mathrm{~h}$, the width of the injury line was quantified. (C) Lactate in the medium was measured when Neo and LOXL-1 cells were cultured for the indicated periods $(12,24,36$ or $48 \mathrm{~h}$ ) as described in Materials and methods. (D) The extracellular $\mathrm{pH}$ of Neo and LOXL-1 cells was measured during the $36 \mathrm{~h}$ incubation period. (E) Western blotting was performed with anti-MCT1/2, MMP2/9, LOXL-1 or $\beta$-actin antibody. (F) Zymography was performed for MMP2/9 activity. ${ }^{*} \mathrm{P}<0.05$, significantly different from Neo cells. Neo, neomycin-resistant vector-transfected. 
A

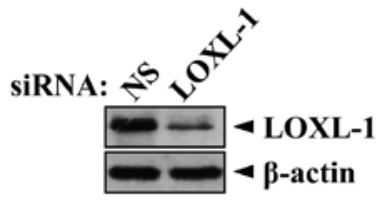

NS SIRNA LOXL-1 siRNA

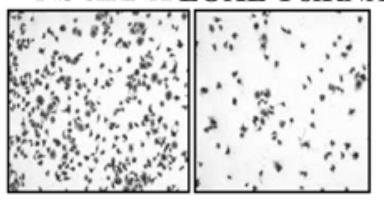

B

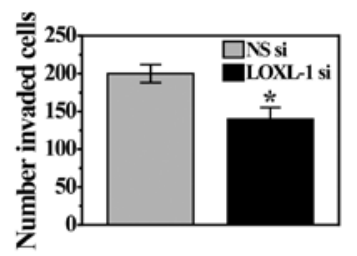

C

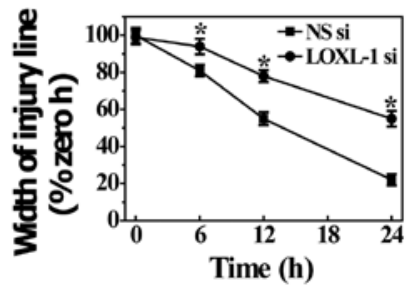

D

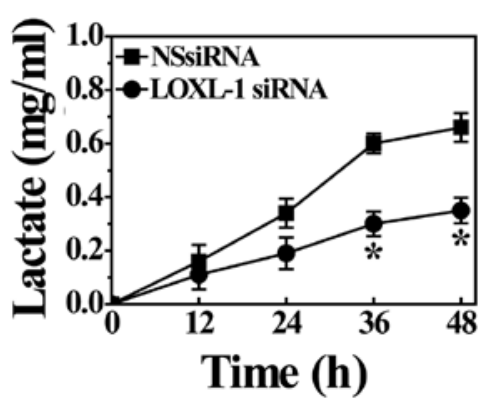

F

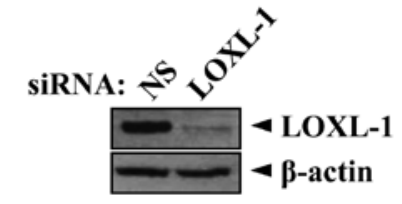

NS SIRNA LOXL-1 si RNA

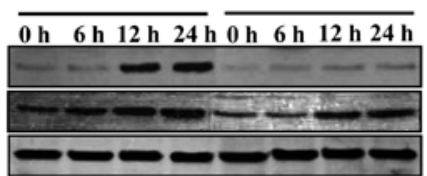

$\mathbf{E}$

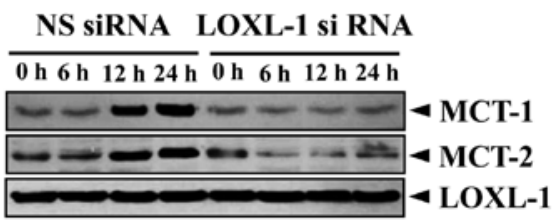

G

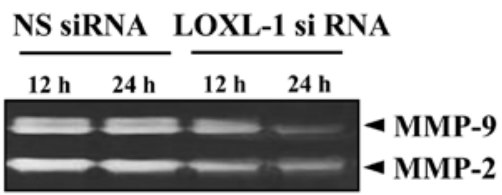

Figure 3. Endogenous LOXL-1 plays a significant role in the extracellular accumulation of lactate and the expression of its transporter, MCT1/2, in in vitro cancer metastasis. (A) HT1080 cells were transfected with non-specific or LOXL-1-specific siRNA and the expression of LOXL-1 was confirmed (upper panel). The invasion analysis was performed as in Fig. 2A. The $0.1 \%$ crystal violet staining cells in the lower chamber are shown (A, lower panel). The number was determined by counting cells in the lower wells. (B) The width of the injury line was quantified at the indicated culturing periods, $0,6,12,18$ or $24 \mathrm{~h}$. (C) Lactate in the medium was measured when non-specific and LOXL-1 siRNA-transfected cells were cultured for the indicated periods (12, 24,36 or 48 h) (D) Western blotting was performed with anti-MCT1/2, MMP2/9, LOXL-1 or $\beta$-actin antibodies. (E) Zymography was performed for MMP2/9 activity. (F) ${ }^{*} \mathrm{P}<0.05$, significantly different from the non-specific siRNA-transfected condition. NSsi, non-specific siRNA.

knock-down cells (Fig. 3B), suggesting that the endogenous expression of LOXL-1 is related to tumor cell invasion. A complementary wound healing assay of in vitro cell migration was also performed. In agreement with the infiltration assay (Fig. 3A and B), the wound healing assay revealed significantly reduced wound closure in LOXL-1 siRNA-transfected cells, compared with non-specific siRNA-transfected cells at 6, 12, 18 and $24 \mathrm{~h}$ after scratching (Fig. 3C). Lactate accumulation was also compared between non-specific and LOXL-1-specific siRNA-transfected cells. Consistent with data regarding LOXL-1 overexpressing cells (Fig. 2C and D), less lactate was accumulated in LOXL-1than in non-specific siRNA-transfected cells (Fig. 3D). The expression of $\mathrm{MCT} 1 / 2$ was also negatively regulated in LOXL-1-specific siRNA-transfected cells (Fig. 3E). When non-specific and LOXL-1 siRNA-transfected cells were cultured, MMP2/9 expression was measured from a point (12 $\mathrm{h}$ after the transfection of siRNAs) that was marked at $0 \mathrm{~h}$.
As expected, the MMP expressions were highly expressed in a time-dependent manner in non-specific siRNA-transfected cells than in LOXL-1 siRNA-transfected cells (Fig. 3F). The MMP2/9 activity was also measured using medium from the 12 - and $24 \mathrm{~h}$-culturing period, which was also counted from the $0 \mathrm{~h}$ point ( $12 \mathrm{~h}$ after the transfection of siRNAs). MMP2/9 was also more activated in non-specific siRNAtransfected cells than in LOXL-1 siRNA-transfected cells (Fig. 3G), demonstrating a consistent role of LOXL-1 on MMP2/9 expression and activity.

LOXL-1 is highly expressed with MCT1/2 and MMP2/9. Consistent with Table I, Fig. 4A shows the higher expression of LOXL-1 in metastatic cancer samples than in primary site samples. Consistent with in vitro data, MCT1/2 was more highly expressed in metastatic cancer samples compared with primary cancer samples. In cancer patients, the invasive phenotype of cancer cells is often associated with an 
A

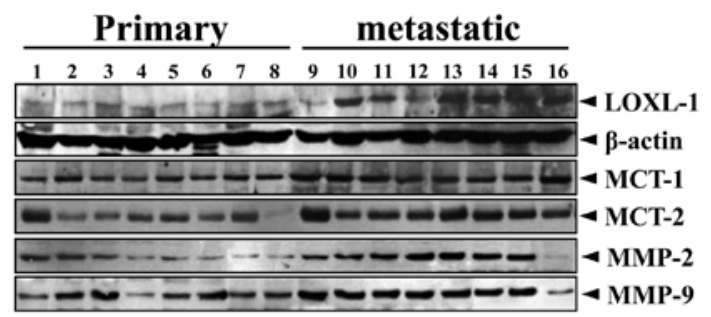

B
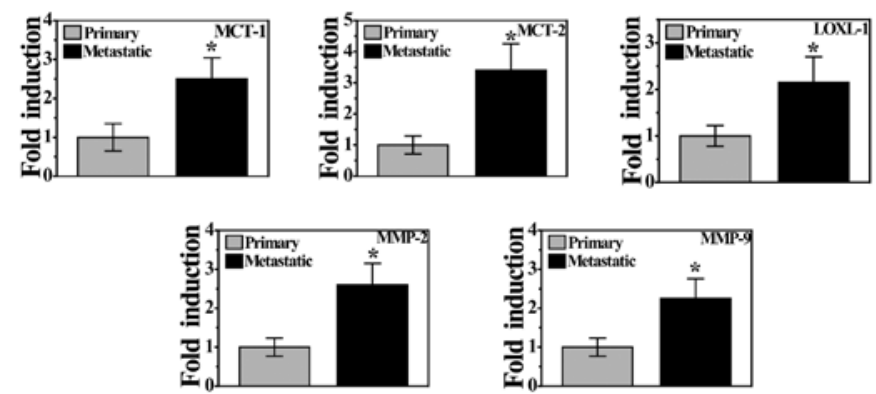

Figure 4. LOXL-1 is highly expressed in metastatic site samples and a correlation with MCT1/2 expression is confirmed. (A) Western blotting was performed with primary and secondary (metastatic) tumor samples from lung cancer patients using anti-LOXL-1, MCT1/2 or MMP2/9 antibodies (B) The quantification for LOXL-1, MCT1/2 or MMP $2 / 9$ was analyzed. ${ }^{*} \mathrm{P}<0.05$, significantly different from primary site samples.

increased expression of MMP-2 and/or MMP-9, which may degrade major structural collagen (26). As expected, MMP-2/9 was highly expressed in the samples from metastatic sites. Fig. 4B clearly shows the quantification of the expression of these proteins.

\section{Discussion}

The present study provides evidence indicating that the expression of LOXL-1, one of the amine oxidases, is involved in non-small cell lung cancer metastasis. Results of the in vitro and in vivo studies also showed LOXL-1-associated cancer metastasis. In this study, MCT1/2 was suggested to be involved in LOXL-1-associated cancer metastasis through lactate accumulation and the consequential acidic extracellular $\mathrm{pH}$ where MMP2/9 was highly activated. Furthermore, among a total of 71 cases of lung carcinoma, LOXL-1 expression was more frequently observed in metastatic sites than in primary sites. Throughout this study, the role of LOXL-1 was clearly linked to cancer metastasis.

LOXL-1, similarly to LOX, plays a critical role in the formation and repair of the ECM by oxidizing lysine residues in elastin and collagen, thereby stabilizing the fibrous proteins $(18,27)$. In addition to its fibrogenic function, LOX expression is associated with tumor suppression and tumor progression, and its role in tumorigenesis appears to be dependent on cellular location, cell type and transformation status (27-32). Microarray studies have shown that the expression of LOX is elevated in hypoxic human tumor cells (33), suggesting that the LOX expression is regulated by hypoxia- inducible factor (HIF) and is associated with hypoxia in human breast, head and neck tumors (28). Furthermore, LOX secreted by hypoxic primary tumor cells accumulates with fibronectin at sites of future metastasis $(34,35)$, suggesting a crucial role for LOX that is secreted by hypoxic tumor cells and is critically involved in a pre-metastatic state formation resulting in cancer metastasis. Possible mechanisms of LOXL-1-related cancer metastasis may also be linked to a hypoxia-associated mechanism. Although the data do not provide any direct evidence regarding hypoxia, indirect phenomena, including lactate accumulation, were demonstrated (Figs. 2C and 3D). Hypoxic status is observed in the areas around tumors due to high proliferation at the primary site, leading to vessel formation through angiogenesis factor activation and further leading to metastasis $(4,9)$. Cancer cells usually facilitate glucose uptake, which is a diagnostic marker of cancer $(5-7,9)$. The expression of lysyl oxidation enzymes is directly linked to collagen cross-linking at a specific site and step; however, the expression is associated with hypoxic status and hypoxia-associated signaling (28,33-35). Therefore, the expression of LOXL-1 may also be linked to hypoxic cancer status, leading to high glucose uptake and the resultant lactate production.

To assess the mechanism of LOXL-1-associated lactate accumulation, the expression of MCT1/2 was also shown. In LOXL-1 overexpressing cells, MCT1/2 was highly expressed (Fig. 2E). Furthermore, LOXL-1 knockdown inhibited the expression of $\mathrm{MCT} 1 / 2$, indicating the upstream role of LOXL-1 on MCT1/2 expression (Fig. 3E). MCT opening results in the extracellular accumulation of lactate and acidic extracellular surroundings (25). The cancer model showed the extrusion of lactate but not lactate uptake through MCT, which is correlated to lactate accumulation in the extracellular cancer environment (14). Considering that a number of human tumors are hypoxic $(3,17)$, probably due to the compromised micro-circulation within tumors, LOX/LOXL-1 expression in hypoxic tumors may be associated with a more aggressive malignant phenotype and increased risk of metastasis.

In clinical sample analysis, cancer tissues from metastatic sites revealed higher expression of LOXL-1 than those from primary site tissues in non-small cell lung carcinoma patients (Fig. 4A and B). In accordance with LOXL-1, the lactate transporter MCT1/2 was highly expressed in the metastatic cancer samples. In this study, LOXL-1 is suggested as a cancer metastasis-associated protein, likely correlated to cancer hypoxic status-associated metastasis. Similarly, MCT1 is significantly increased in breast carcinomas compared with normal breast tissue and, significantly, MCT1 is associated with poor prognostic variables including high-grade tumors (36). MCT1 expression is also associated with advanced gastric carcinoma and lymph node metastasis (37).

This study also demonstrates a favorable correlation between MMP2/9 and MCT expression in LOXL-1-expressing cells (Fig. 2E and F). The critical pathological turning point in cancer is the initiation of local invasion, leading to the dissemination of tumor cells. Invasion is an active translocation of neoplastic cells across tissue boundaries through host cellular and extracellular matrix barriers $(38,39)$, where MMPs are directly involved. Most invasive colonic, gastric, breast and ovarian carcinomas have high MMP expression, particu- 
larly MMP-2 and MMP-9 (40). The evidence for MMPs as active contributors to cancer progression stems from animal studies (41). Furthermore, acidic media ( $\mathrm{pH}$ 5.4-6.5) increase MMP activity in cell culture (3), in which expression correlates with tumor aggressiveness.

In conclusion, LOXL-1 is closely related to lung cancer metastasis, and MMP2/9 is also highly activated. MCT1/2, a lactate transporter, is involved in LOXL-1-associated cancer metastasis by contributing to an acidic extracellular environment. This study suggests that LOXL-1 is a potential drug target for cancer metastasis.

\section{Acknowledgements}

This study was supported by the Korea Research Foundation (KRF-2009-0087202 and KRF-2008-E00042) and partly by the National Research Foundation (NRF-2010-0029497). The biospecimens for this study were provided by the Biobank of Chonbuk National University Hospital, a member of the National Biobank of Korea, which is supported by the Ministry of Health, Welfare and Family Affairs.

\section{References}

1. Driouch K, Landemaine T, Sin S, Wang S and Lidereau R: Gene arrays for diagnosis, prognosis and treatment of breast cancer metastasis. Clin Exp Metastasis 24: 575-585, 2007.

2. Iles RK: Ectopic hCG $\beta$ expression by epithelial cancer: malignant behaviour, metastasis and inhibition of tumor cell apoptosis. Mol Cell Endocrinol 262: 264-270, 2007.

3. Rofstad EK, Mathiesen B, Kindem K and Galappathi K: Acidic extracellular $\mathrm{pH}$ promotes experimental metastasis of human melanoma cells in athymic nude mice. Cancer Res 66: 6699-6707, 2006.

4. Gatenby RA and Gillies RJ: Why do cancers have high aerobic glycolysis? Nat Rev Cancer 4: 891-899, 2004

5. Gatenby RA, Gawlinski ET, Gmitro AF, Kaylor B and Gillies RJ: Acid-mediated tumor invasion: a multidisciplinary study. Cancer Res 66: 5216-5223, 2006.

6. Bhujwalla ZM, Artemov D, Ballesteros P, Cerdan S, Gillies RJ and Solaiyappan M: Combined vascular and extracellular $\mathrm{pH}$ imaging of solid tumors. NMR Biomed 15: 114-119, 2002.

7. Schornack PA and Gillies RJ: Contributions of cell metabolism and $\mathrm{H}^{+}$diffusion to the acidic $\mathrm{pH}$ of tumors. Neoplasia 5: 135-145, 2003.

8. Halestrap AP and Meredith D: The SLC16 gene family - from monocarboxylate transporters (MCTs) to aromatic amino acid transporters and beyond. Pflugers Arch 447: 619-628, 2004.

9. Stubbs M, Veech RL and Griffiths JR: Tumor metabolism: the lessons of magnetic resonance spectroscopy. Adv Enzyme Regul 35: 101-115, 1995.

10. Skøyum R, Eide K, Berg K and Rofstad EK: Energy metabolism in human melanoma cells under hypoxic and acidic conditions in vitro. Br J Cancer 76: 421-428, 1997.

11. Walenta S, Salameh A, Lyng H, Evensen JF, Mitze M, Rofstad EK and Mueller-Klieser W: Correlation of high lactate levels in head and neck tumors with incidence of metastasis. Am J Pathol 150: 409-415, 1997.

12. Brizel DM, Schroeder T, Scher RL, Walenta S, Clough RW, Dewhirst MW and Mueller-Klieser W: Elevated tumor lactate concentrations predict for an increased risk of metastases in head-and-neck cancer. Int J Radiat Oncol Biol Phys 51: 349-353, 2001.

13. Wahl ML, Pooler PM, Briand P, Leeper DB and Owen CS: Intracellular $\mathrm{pH}$ regulation in a nonmalignant and a derived malignant human breast cell line. J Cell Physiol 183: 373-380, 2000.

14. Fang J, Quinones QJ, Holman TL, Morowitz MJ, Wang Q, Zhao H, Sivo F, Maris JM and Wahl ML: The $\mathrm{H}^{+}$-linked monocarboxylate transporter (MCT1/SLC16A1): a potential therapeutic target for high-risk neuroblastoma. Mol Pharmacol 70: 2108-2115, 2006.
15. Stock $\mathrm{C}$ and Schwab A: Protons make tumor cells move like clockwork. Pflugers Arch 458: 981-992, 2009.

16. Stüwe L, Müller M, Fabian A, Waning J, Mally S, Noël J, Schwab A and Stock C: pH dependence of melanoma cell migration: protons extruded by NHE1 dominate protons of the bulk solution. J Physiol 585: 351-360, 2007.

17. Lee GH, Yan C, Shin SJ, Hong SC, Ahn T, Moon A, Park SJ, Lee YC, Yoo WH, Kim HT, Kim DS, Chae SW, Kim HR and Chae HJ: BAX inhibitor-1 enhances cancer metastasis by altering glucose metabolism and activating the sodiumhydrogen exchanger: the alteration of mitochondrial function. Oncogene 29: 2130-2141, 2010.

18. Akiri G, Sabo E, Dafni H, Vadasz Z, Kartvelishvily Y, Gan N, Kessler O, Cohen T, Resnick M, Neeman M and Neufeld G: Lysyl oxidase-related protein-1 promotes tumor fibrosis and tumor progression in vivo. Cancer Res 63: 1657-1666, 2003.

19. Nishimura R, Hasebe T, Tsubono $Y$, Ono M, Sugitoh M, Arai $\mathrm{T}$ and Mukai K: The fibrotic focus in advanced colorectal carcinoma: a hitherto unrecognized histological predictor for liver metastasis. Virchows Arch 433: 517-522, 1998.

20. Ellenrieder V, Alber B, Lacher U, Hendler SF, Menke A, Boeck W, Wagner M, Wilda M, Friess H, Büchler M, Adler G and Gress TM: Role of MT-MMPs and MMP-2 in pancreatic cancer progression. Int J Cancer 85: 14-20, 2000.

21. Duffy MJ, Maguire TM, Hill A, McDermott E and O'Higgins N: Metalloproteinases: role in breast carcinogenesis, invasion and metastasis. Breast Cancer Res 2: 252-257, 2000.

22. Sawada S, Murakami K, Murata J, Tsukada K and Saiki I: Accumulation of extracellular matrix in the liver induces high metastatic potential of hepatocellular carcinoma to the lung. Int J Oncol 19: 65-70, 2001.

23. Decitre M, Gleyzal C, Raccurt M, Peyrol S, Aubert-Foucher E, Csiszar K and Sommer P: Lysyl oxidase-like protein localizes to sites of de novo fibrinogenesis in fibrosis and in the early stromal reaction of ductal breast carcinomas. Lab Investig 78: 143-151, 1998.

24. Kirschmann DA, Seftor EA, Fong SF, Nieva DR, Sullivan CM, Edwards EM, Sommer P, Csiszar K and Hendrix MJ: A molecular role for lysyl oxidase in breast cancer invasion. Cancer Res 62: 4478-4483, 2002.

25. Pinheiro C, Longatto-Filho A, Scapulatempo C, Ferreira L, Martins S, Pellerin L, Rodrigues M, Alves VA, Schmitt F and Baltazar F: Increased expression of monocarboxylate transporters 1,2, and 4 in colorectal carcinomas. Virchows Arch 452: 139-146, 2008.

26. Castellano G, Malaponte G, Mazzarino MC, Figini M, Marchese F, Gangemi P, Travali S, Stivala F, Canevari S and Libra M: Activation of the osteopontin/matrix metalloproteinase-9 pathway correlates with prostate cancer progression. Clin Cancer Res 14: 7470-7480, 2008.

27. Kagan HM and Li W: Lysyl oxidase: properties, specificity, and biological roles inside and outside of the cell. J Cell Biochem 88: 660-672, 2003 .

28. Erler JT, Bennewith KL, Nicolau M, Dornhöfer N, Kong C, Le QT, Chi JT, Jeffrey SS and Ciaccia AJ: Lysyl oxidase is essential for hypoxia-induced metastasis. Nature 440: 1222-1226, 2006.

29. Kaneda A, Wakazono K, Tsukamoto T, Watanabe N, Yagi Y, Tatematsu M, Kaminishi M, Sugimura T and Ushijima T: Lysyl oxidase is a tumor suppressor gene inactivated by methylation and loss of heterozygosity in human gastric cancers. Cancer Res 64: 6410-6415, 2004.

30. Csiszar K, Fong SF, Ujfalusi A, Krawetz SA, Salvati EP Mackenzie JW and Boyd CD: Somatic mutations of the lysyl oxidase gene on chromosome $5 \mathrm{q} 23.1$ in colorectal tumors. Int J Cancer 97: 636-642, 2002.

31. Palamakumbura AH, Jeay S, Pischon N, Sommer P, Sonenshein GE and Trackman PC: The propeptide domain of lysyl oxidase induces phenotypic reversion of ras-transformed cells. J Biol Chem 279: 40593-40600, 2004.

32. Payne SL, Fogelgren B, Hess AR, Seftor EA, Wiley EL, Fong SF, Csiszar K, Hendrix MJ and Kirschmann DA: Lysyl oxidase regulates breast cancer cell migration and adhesion through a hydrogen peroxide-mediated mechanism. Cancer Res 65: 11429-11436, 2005.

33. Denko NC, Fontana LA, Hudson KM, Sutphin PD, Raychaudhuri S, Altman R and Ciaccia AJ: Investigating hypoxic tumor physiology through gene expression patterns. Oncogene 22: 5907-5914, 2003. 
34. Kaplan RN, Riba RD, Zacharoulis S, Bramley AH, Vincent L, Costa C, MacDonald DD, Jin DK, Shido K, Kerns SA, Zhu Z, Hicklin D, Wu Y, Port JL, Altorki N, Port ER, Ruggero D, Shmelkov SV, Sensen KK, Rafii S and Lyden D VEGFR1-positive haematopoietic bone marrow progenitors initiate the pre-metastatic niche. Nature 438: 820-827, 2005.

35. Erler JT, Bennewith KL, Cox TR, Lang G, Bird D, Koong A, Le QT and Giaccia AJ: Hypoxia-induced lysyl oxidase is a critical mediator of bone marrow cell recruitment to form the premetastatic niche. Cancer Cell 15: 35-44, 2009.

36. Pinheiro C, Albergaria A, Paredes J, Sousa B, Dufloth R, Vieira D, Schmitt F and Baltazar F: Monocarboxylate transporter 1 is up-regulated in basal-like breast carcinoma. Histopathology 56: 860-867, 2010.

37. Pinheiro $\mathrm{C}$, Longatto-Filho A, Simões K, Jacob CE, Bresciani CJ, Zilberstein B, Cecconello I, Alves VA, Schmitt F and Baltazar F: The prognostic value of CD147/EMMPRIN is associated with monocarboxylate transporter 1 co-expression in gastric cancer. Eur J Cancer 45: 2418-2424, 2009.
38. Westermarck $\mathbf{J}$ and Kahari VM: Regulation of matrix metalloproteinase expression in tumor invasion. FASEB J 13:781-792, 1999.

39. Jones LE, Humphreys MJ, Campbell F, Neoptolemos JP and Boyd MT: Comprehensive analysis of matrix metalloproteinase and tissue inhibitor expression in pancreatic cancer: increased expression of matrix metalloproteinase-7 predicts poor survival. Clin Cancer Res 10: 2832-2845, 2004.

40. Boyd RS and Balkwill FR: MMP-2 release and activation in ovarian carcinoma: the role of fibroblasts. Brit J Cancer 80: 315-321, 1999.

41. Schmalfeldt B, Prechtel D, Härting K, Späthe K, Rutke S, Konik E, Fridman R, Berger U, Schmitt M, Kuhn W and Lengyel E: Increased expression of matrix metalloproteinases (MMP)-2, MMP-9, and the urokinase-type plasminogen activator is associated with progression from benign to advanced ovarian cancer. Clin Cancer Res 7: 2396-2404, 2001. 